\title{
Ensaio
}

\section{Outras margens da revisão de textos: experiências com o literário}

\section{Other margins of proofreading: experiences with the literary}

\author{
Ana Elisa Ribeiro'(i) \\ 'Centro Federal de Educação Tecnológica de Minas Gerais, Departamento de Linguagem e Tecnologia, \\ Minas Gerais, MG, Brasil
}

\section{RESUMO}

Neste ensaio, abordamos os saberes e as práticas mais específicos da revisão do texto literário, com base em outros trabalhos na área, além de fazermos breve discussão de casos empíricos de revisão de textos literários contemporâneos. Trata-se de um trabalho de cunho ensaístico, que busca defender a ideia de que para um texto literário é necessária uma revisão também literária, isto é, uma prática de revisão mais sensível às questões que tocam esta arte, baseadas em decisões prévias ou acordadas diligentemente com editores/as e autores/as.

Palavras-chave: Revisão de Textos; Revisão do Texto Literário; Produção Editorial; Literatura Contemporânea

\section{ABSTRACT}

In this essay, we approach the more specific knowledges and practices concerning the proofreading of literary texts, based in other works of the area as well as briefly presenting empirical instances of proofreading of contemporary literary texts. It is an essayistic approach, that intends to advocate the idea that a literary text demands an equally literary proofreading, i. e., a more sensitive proofreading practice related to the questions concerning this art, based in previous or agreed decisions between proofreaders, publishers and authors.

Keywords: Proofreading; Proofreading of Literary Texts; Editorial Production; Contemporary Literature 


\section{INTRODUÇÃO: PRINCÍPIO, O VERBO}

"A gente gostava das palavras quando elas perturbavam o sentido normal das ideias. Porque a gente também sabia que só os absurdos enriquecem a poesia."

"Nossas palavras se ajuntavam uma na outra por amor e não por sintaxe."

- Manoel de Barros, em Menino do Mato (Alfaguara, 2015, p. 14-15)

Não estão aqui por acaso as epígrafes retiradas de poemas de Manoel de Barros, um dos mais peculiares e mais populares poetas contemporâneos brasileiros. Talvez ele nos ajude a dizer das especificidades da revisão do texto literário, explicitando, poeticamente, do ponto de vista do autor, de que ordem são certas escolhas e por que a revisão desse gênero de texto demanda certos conhecimentos e procedimentos também especializados do/a profissional de língua, isto é, o/a revisor/a1.

A revisão especificamente do texto literário dispõe, em português, de ainda menos estudos acadêmicos do que a revisão, de modo geral. No Brasil, é possível encontrar, há décadas, manuais de revisão generalistas, tal como apontamos em Ribeiro (2018)², em sua maioria prescritivistas ou adotantes de uma visão do/a revisor/a como um/a profissional defensor das gramáticas normativas e das regras unificadoras

\footnotetext{
${ }^{1}$ Ao longo deste artigo, empregaremos o recurso da barra para sempre considerar profissionais dos gêneros masculino e feminino. A base deste texto é nossa participação em uma mesa-redonda do IV Fórum Nacional sobre a Formação e a Atuação Profissional do Revisor de Textos, ocorrido em Belo Horizonte, em novembro de 2019, organizado por professores e pesquisadores do Centro Federal de Educação Tecnológica de Minas Gerais (CEFET-MG) e da Pontifícia Universidade Católica de Minas Gerais (PUC Minas). Naquela ocasião, de posse da lista com os nomes de mais de uma centena de inscritos/as em evento tão específico, verificamos que $82 \%$ eram mulheres, o que talvez reflita a situação desse mercado, por muitas razões. É, portanto, no mínimo justo que tratemos do tema considerando a força de trabalho formada pelas revisoras, provável maioria não apenas neste evento.

2 Embora citemos aqui o texto de 2018, antes de ser capítulo de livro, ele foi um artigo publicado nos anais do Congresso Brasileiro de Ciências da Comunicação, em 2007, o que mostra que há tempos vimos nos ocupando deste tema e fazendo movimentos que outros/as pesquisadores/as também fazem.
} 
ou padronizadoras ${ }^{3}$. Mais recentemente, no entanto, talvez sob a influência já de pesquisas mais atuais (de cerca de vinte anos para cá), é possível encontrar, além dos manuais, estudos que tratam da atuação dos/as revisores/as como profissionais especializados, sim, mas capazes de distinguir, entre linguagens e gêneros discursivos, os tipos de revisão que deverão fazer, a fim de colaborar com o projeto enunciativo de seus clientes ${ }^{4}$. A formação mais diversa, mais teoricamente informada e até mais consciente desses/as profissionais é preconizada por trabalhos científicos publicados em livros e revistas acadêmicos, o que termina por ampliar as possibilidades de debate e formação continuada daqueles/as que atuam nesta área, tanto como autônomos/as quanto como funcionários/as de editoras e outras empresas que lidam com publicações e comunicação.

Com o passar dos anos e a lenta profissionalização do mercado editorial brasileiro, é possível observar mudanças importantes no cenário da formação, do emprego e da educação continuada dos/as revisores. Embora sempre se fale em

\footnotetext{
${ }^{3}$ Temos combatido essa caricatura do revisor como um puro operacionalizador das regras e da prescrição, muito construída pelos manuais e pela imprensa que dá força à ideia de língua como monolito, dando espaço visível a gramáticos e repetidores de "regras gramaticais" sob o rótulo de "dicas" ou aulas de português. Na academia, linguistas também podem promover essa caricatura, indo até ao extremo de detratar a revisão textual e seus profissionais. Já assistimos mesmo a conversas raivosas de acadêmicos sobre a atuação em revisão, com argumentos da sociolinguística e outros. Há mais de década, os conhecimentos da linguística vêm sendo empregados justamente no pensamento sobre as práticas profissionais voltadas aos textos, algo que inegavelmente e há muito tempo faz parte do cenário profissional e das possibilidades de estudantes de Letras, entre outras áreas de formação. O mercado editorial se profissionaliza, muda, exige mais qualificação e, hoje, concilia os estudos informados da linguística e as práticas sociais e profissionais ditas da edição dos textos, em muitos níveis e para muitos propósitos. O/A linguista pode olhar com mais justiça e deixar de pensar que a revisão seja uma tarefa ou uma prática profissional monolítica, executada por um profissional dócil e subjugado, passando a notar a imensa paleta de questões de linguagem com que tal trabalhador/a lida, sobre as quais pensa e precisa tomar decisões informadas, inclusive e principalmente pelos próprios conhecimentos de linguística.

${ }^{4}$ Não teremos pudor em chamar de cliente a esta pessoa ou organização que demanda serviços de revisão. Considerando que a revisão seja um trabalho remunerado e especializado, muitas vezes regulado por um contrato ou parâmetros negociados, reconhecida entre as ocupações brasileiras (CBO) e plenamente conhecida no âmbito da produção editorial, é mesmo ao cliente que nos referimos. Mesmo que o/a trabalhador/a seja formado/a em Letras, curso tradicionalmente ligado a outros campos do trabalho, ele atua no âmbito corporativo ou do microempreendendor individual, como uma nanoempresa que paga impostos e precisa receber por seus serviços de qualidade.
} 
valorização desse/a profissional, são relativamente recentes os cursos universitários francamente dedicados à formação de revisores/as, assim como são muito contemporâneas as mudanças tecnológicas e do mundo do trabalho em que revisores e revisoras atuam, dia após dia ${ }^{5}$. Certamente, entre as profissões que demandam atualização constante está a de revisor/a, o que tem sido estimulado pela existência de cursos menos ou mais curtos, legitimados por instituições idôneas, oferecidos em modalidades presenciais e virtuais, suportados por uma bibliografia também teórica, que se compõe tanto de obras esparsas, na forma de manuais ou livros organizados, quanto de coleções especializadas de títulos dedicados aos estudos acadêmicos sobre a revisão textual ${ }^{6}$. Pode-se mesmo dizer que esse tipo de pesquisa e atuação técnico-acadêmica não seja privilégio do Brasil, havendo bibliografia e debates também em outros países.

Especificamente sobre a revisão do texto literário, os trabalhos são encontrados esparsamente, como capítulos de livros e artigos em revistas acadêmicas, nestes casos, felizmente, de acesso aberto, o que aponta para uma diferença importante de circulação entre os livros e os textos avulsos.

\footnotetext{
${ }^{5}$ Para pensar sobre a formação específica na área, pode-se ler, por exemplo, Muniz Jr. (2018) e Baptista, Ribeiro e Vilella (2018).

${ }^{6}$ Algumas iniciativas têm o intuito de reunir obras que tratem de edição, história do livro e temas afins. Editoras universitárias como a Edusp e a Unesp publicam belíssimas coleções sobre livros, assim como a editora Ateliê, em São Paulo. É possível encontrar livros esparsos em muitas editoras, em especial de quinze ou vinte anos para cá. Alguns manuais específicos sobre revisão de textos, como os citados em Perez e Boenavides (2017) e também em Ribeiro (2018), são relativamente conhecidos, em especial quando foram publicados por editoras como a Ática, cujo poder de distribuição era maior. Trata-se de manuais já "antigos", alguns datados dos anos 1970. Em vários casos, são difíceis de encontrar, embora hoje em dia possamos contar com serviços de livrarias e sebos on-line. Recentemente, a editora Moinhos, em Belo Horizonte, publicou o manual de uma revisora conhecida nas redes sociais digitais. Trata-se de um material interessante, e dos menos prescritivistas, para a formação de iniciantes (MACHADO, 2018). Existe uma coleção de estudos acadêmicos específica sobre revisão chamada "Questões contemporâneas de edição, preparação e revisão textual", publicada desde 2016 pela editora Artigo A, selo da editora Gulliver, com sede na cidade de Divinópolis, Minas Gerais. Embora seja uma editora pequena, os livros têm distribuição nacional por meio de livrarias virtuais. Tal coleção conta, em 2020, com quatro volumes e um em preparação.
} 


\section{REVISAR LITERATURA: QUE IMPLICAÇÕES TEM?}

Embora seja importante conceituar literatura a fim de tratar de certas obras, não o faremos neste artigo. Literatura, aqui, para os efeitos de uma discussão sobre práticas de revisão textual, será o que os/as autores/as clientes chamam de literatura. Mais amplamente, vamos considerar que textos literários podem ser poemas, romances, contos, peças de teatro e obras dirigidas à infância e à juventude, geralmente a demandarem tratamento editorial ou porque serão publicadas por seus autores (em regime de autopublicação ou por editoras independentes) ou porque serão publicadas por editoras cujos processos editoriais são mais complexos e detalhistas. São casos diferentes, do ponto de vista da produção editorial, mas igualmente demandantes de profissionais da revisão.

Também em relação à "cena" em que essa revisão ocorre, profissionais especialistas em textos podem atuar como funcionários de empresas, i. é, geralmente casas editoriais maiores ou mais economicamente potentes, ou como autônomos/freelancers, prestando serviços sem vínculo empregatício, geralmente da maneira informal ou, em anos mais recentes, como microempreendedores individuais, sem fidelidade a uma empresa apenas e gerindo autonomamente aceites, recusas, prazos, tipos de trabalho e formas de captação financeira.

Como a literatura está geralmente relacionada à publicação de livros (impressos ou digitais), é mais comum que um/a revisor/a seja consultado/a para um trabalho que será posto à disposição de um público eventualmente mais amplo. Com isso, aumentam também as chances de que esse/a revisor/a deva estabelecer contato com um/a editor/a, que atuará como mediador da relação com o/a autor/a do texto. Arriscamo-nos a dizer que o contato direto com o/a autor/a do texto será ainda mais comum nesta cena, em que a autopublicação ou a publicação em casas muito pequenas, de processo editorial abreviado, é cada vez mais comum e ocorre fartamente há pelo menos três décadas, no Brasil. 
Podemos dizer, então, de dois mundos ou duas margens na edição do texto literário: o das poucas e concentradas editoras grandes 7 , em que podem atuar preparadores e editores de texto, além de revisores, tantas vezes mais de um profissional por texto; e o das editoras pequenas, maioria no país, começo e meio de tudo para grande parte dos/as autores/as e aspirantes, responsáveis pela renovação, pela oxigenação, pela coragem dos livros literários que renovam a paisagem artística, em que os textos podem não passar sequer por um/a revisor/a. É comum entre os/as escritores/as que peçam a um/a colega interlocutor/a para revisar, o que pode ser fatalmente uma leitura crítica, mais que uma revisão de língua.

Então, embora seja um mercado possível, a revisão do texto literário não costuma ser a atuação mais comum de revisores/as autônomos/as. No entanto, se houver chance, demandará do/a profissional conhecimentos, comportamentos e procedimentos sensíveis a um campo cheio de especificidades e peculiaridades, como apontam diversos trabalhos acadêmicos. É o caso de um dos mais citados textos sobre o tema, de autoria de duas pesquisadoras da Universidade Federal de Ouro Preto e da Pontifícia Universidade Católica de Minas Gerais (PERPÉTUA; GUIMARÃES, 2010). Segundo Elzira Divina Perpétua e Raquel Junqueira Guimarães,

é fundamental compreender que a tarefa de revisar um texto literário desloca o profissional da revisão para o território da crítica, transformando o revisor num crítico privilegiado, uma vez que seu contato com a obra ocorre no primeiro estágio da criação, aquele em que o texto existe apenas para um número limitado de leitores, antes da publicação - ou antes mesmo de chegar à editora, onde passará por outros processos de leitura. (PERPÉTUA; GUIMARÃES, 2010, p. 196).

Já de início, as autoras advertem que consideram o texto literário revisável, isto é, admitem estar ele entre duas margens: não é "solo sagrado", mas também não está

\footnotetext{
${ }^{7}$ Dos anos 1990 em diante, o mercado editorial mundial experimentou uma grande e perigosa concentração, isto é, editoras gigantes e conglomerados de mídia compraram boa parte das editoras menores, em muitos países, inclusive no Brasil. Tal movimentação acarretou mudanças na cadeia produtiva do livro e, também, uma reação. Ajudadas pelas tecnologias digitais, pelo barateamento e pela desespecialização de certas etapas da edição, surgiu uma miríade de pequenas editoras, as ditas "independentes", que passaram a defender o que foi chamado de bibliodiversidade. Para mais detalhes, ver, por exemplo, Colleu (2008). Para uma análise mais recente, ver De Diego (2015).
} 
desvestido de especificidades. É uma "obra de arte em processo de constituição" (p. 195), o que torna o/a revisor/a um "leitor privilegiado" (p. 195). Perpétua e Guimarães (2010) mencionam casos conhecidos entre escritores/as consagrados/as, abordam questões de autoria e estilo, sempre espinhosas, e citam o historiador Roger Chartier, a fim de defender a ideia de que os processos editoriais pelos quais um texto original passa é que o transformam em livro. Ao longo do artigo, são explicitados conhecimentos que um/a revisor/a deve construir para alcançar bons resultados em seu trabalho, em especial no trato com textos literários: memória de leitura (uma espécie de repertório amplo de leituras que serão sempre chamadas à situação da revisão), conhecimento histórico e cultural, além do conhecimento da língua, i. é, gramática e teorizações linguísticas e literárias.

Baseiam-se em Perpétua e Guimarães (2010) os trabalhos de Almeida (2019) e Pinto \& Marques (2019), publicados na mesma revista e traçados conforme um desenho metodológico composto por entrevistas com revisores/as que lidam, com alguma frequência, com textos literários. Tais entrevistas são pouco exploradas, mas servem para que as pesquisadoras cheguem à conclusão de que, sim, o/a revisor/a do texto literário lida com a "licença poética" e com questões de autoria que envolvem egos, estilos, intenções muito vivas e mesmo disputas simbólicas. Ao/à revisor/a caberia reconhecer ou identificar cada situação como caso único, sendo sensível ao nível de diálogo que precisa ter com autores e/ou editores, em cada processo de revisão, edição e publicação. Novamente, em ambos os textos são mencionados casos de escritores consagrados, que passam a valer como argumento sobre os procedimentos mais adequados em processos de revisão do texto literário: diálogo e interação com os/as envolvidos/as.

Conclusão semelhante tiram Perez e Boenavides (2017), só que fortemente embasados em Bakhtin, no que investem a maior parte das páginas de seu artigo. Partindo da ideia de que "a relação dos escritores com os revisores de texto é 
tradicionalmente tensa" ${ }^{8}$ (р. 114), embora escritores normalmente admitam a importância da revisão, os pesquisadores passam a tratar dos saberes fundamentais de um/a profissional revisor/a e chegam à conclusão de que revisar é muito mais que apenas saber gramática, como outros artigos também mostram, com farta exposição de exemplos. Neste texto, Perez e Boenavides (2017) evocam José Saramago e seu personagem revisor, estratégia também usada em outros trabalhos sobre o tema, vez que História do cerco de Lisboa tornou-se uma das obras literárias mais conhecidas por esta categoria profissional, que talvez até se orgulhe de um enredo em que um revisor é o protagonista. Segundo os pesquisadores, caberia ao/à revisor/a identificar, no texto em revisão, o que é "erro" e o que é recurso pertinente à criação literária.

Valendo-se também de Saramago e de Bakhtin, Oliveira (2012) trata da revisão do texto literário nas mesmas bases que outros estudos, analisando um corpus de entrevistas com revisores experientes e analisando suas respostas. $\mathrm{Na}$ conclusão, a pesquisadora defende o respeito à autoria e o diálogo aberto entre profissionais - autor/a e revisor/a, única forma de atuar entre as especificidades deste campo.

Para casos estrangeiros, valemo-nos de dois artigos em língua espanhola, em ambos os casos algo próximos dos estudos recentes encontrados no Brasil. 0 primeiro é o trabalho do filólogo espanhol Juan António Frago (2019) sobre versões do Quixote, uma das obras mais estudadas de todos os tempos. A certa altura de sua análise linguística, o pesquisador aponta as arbitrariedades problemáticas durante processos de edição de versões da obra de Cervantes. A despeito de sua grande especificidade científica e de não tratar nominalmente da revisão de textos, o trabalho é interessante por capturar exatamente o que as decisões editoriais podem acarretar em uma obra literária da monta de um Quixote. Obviamente, os

\footnotetext{
${ }^{8}$ O sociólogo português Nuno Medeiros (2012) comenta a relação entre escritores e editores, também tradicionalmente tensa, embora se constitua como uma dependência ou uma "cooperação antagonística", ao citar a expressão de William Graham Summer. As fricções entre esses interlocutores parecem ser constitutivas da relação.
} 
processos editoriais do século XXI são completamente outros, e talvez sejam até mais "seguros", nesse sentido.

Já o artigo das argentinas Negroni e Estrada (2006), mais de uma década anterior, discutia as "competências" do que os hispânicos chamam de "corretor de estilo", objetivando responder à pergunta: corretor ou corruptor? Partindo da história do livro desde os manuscritos, a fim de explicitar as existências e funções desse personagem da cadeia produtiva editorial através dos séculos, as autoras empregam noções que se afinam às teorias atuais sobre "competências e habilidades", fundamentadas em Noam Chomsky, para tratar dos saberes e da formação do/a revisor/a de textos, elencando então aspectos enciclopédicos, gramaticais e textuais que consideram imprescindíveis ao/à profissional. Tais aspectos são destrinchados com base em teorias linguísticas que passam pela gramática e pela linguística de texto de Halliday e Hasan ou Robert de Beaugrande, desaguando em uma conclusão: "Revisar é então uma técnica, que se nutre de conhecimentos prévios e de procedimentos específicos que são factíveis de ser adquiridos com a prática. Mas também é uma arte, já que não existe uma única versão possível para revisar um texto" 9 .

Das leituras aqui sumarizadas, podemos iluminar algumas estratégias comuns. Uma delas é: não se estuda a revisão do texto literário sem dispor de exemplos e casos, geralmente situações que se tornam "folclóricas" com escritores/as consagrados/as. É o que não nos faltará, aqui.

\section{CADA CASO É UM CASO}

A fim de levar à sumária mas importante ideia de que para o texto literário cabe uma revisão também literária, lançaremos mão do mesmo expediente de outros/as pesquisadores/as em seus textos sobre o tema: narrar casos cujos/as

\footnotetext{
${ }^{9}$ A tradução livre é nossa. Em espanhol, a palavra usada é "corrección", o que, em português, tem sentido diferente. Nos estudos sobre a revisão, temos evitado a ideia de "correção", em favor de uma noção mais colaborativa e que não necessariamente atue sobre "erros".
} 
protagonistas sejam revisores/as e escritores/as. No entanto, aqui, os casos são recentes, com autores/as contemporâneos/as, e fazem parte de experiências nossas na revisão textual com escritores e escritoras que talvez ainda estejam distantes de um eventual folclore que possam compor mais adiante, se algum/alguma desses/as autores se consagrar, em nossa literatura.

\subsection{Post mortem}

A primeira experiência que queremos considerar, no âmbito da revisão de textos literários, é a de revisar o original da obra de uma autora já falecida, por desejo dela quando viva e da família, texto que resultava da digitação de uma série de cadernos manuscritos deixados pela autora. O volume a ser revisado tinha mais de uma centena de páginas digitadas em Word, fiéis à grafia da autora, que deveriam passar por uma revisão sensível às seguintes questões: correção gramatical, eliminando o que fosse evidentemente "erro", segundo a gramática normativa; manutenção de marcas peculiares à fala das personagens e relativas ao tom mormente oral de todo o texto, que era um relato longo sobre a história da família desde a infância da autora até seus primeiros anos de casamento; atualização de ortografia, eliminando itens originalmente escritos em grafias antigas do português brasileiro, com consoantes dobradas e acentuação de outros tempos.

O texto a ser revisado, portanto, era uma espécie de herança de família; a realização de um desejo post mortem da matriarca; escrito ao longo de sua juventude, i. é, em outro tempo histórico, com o português de outra época, por uma mulher de escolaridade básica, embora culta; com marcas claras de oralidade e ausência de marcações de fala convencionais, como travessões ou aspas, embora houvesse ali infinitos diálogos; considerando-se o cotejo com os manuscritos, nos quais era possível tirar dúvidas sobre palavras em desuso ou muito locais, em certa cidade do interior mineiro. 
Nos primeiros encontros para discutir uma espécie de briefing desta revisão, que ocorreria no arquivo .doc, sem marcações automáticas mas com marcação manual de cores, levantou-se uma questão: o texto tinha qualidades literárias, além de ser um documento histórico, sendo comparado a obras como as de Helena Morley ${ }^{10}$ e outras narradoras conhecidas. De fato, era melhor.

Era preciso pensar e fazer opções, assim como fazem os/as tradutores/as, embora dentro da mesma língua ${ }^{11}$. Seria mesmo necessário atualizar a ortografia conforme o Acordo Ortográfico vigente em 2018? Isso não tiraria um dos "charmes" da escrita da autora? A opção foi por atualizar, já que parte da família considerava essa desatualização um "erro" que poderia "macular a imagem da autora". Seria necessário inserir marcas convencionais de diálogo? Não seria intromissão demais, num texto que, embora sem essas marcas, deixava razoavelmente claros tais diálogos? Sim, era intromissão demais. A composição do texto foi mantida conforme a escrita original.

Esse tipo de decisão resultou num conjunto de critérios que foi levado em conta ao longo de toda a revisão e que era exclusivo daquele trabalho, para aquela situação peculiar. Ainda assim, pós-revisão, o texto suscitou debates e dúvidas, conforme a avaliação de quem lia o resultado, que considerava menos ou mais "erradas" certas escolhas da autora. Ela, no entanto, não podia mais encerrar a discussão ou dialogar com a revisora. Tratava-se de um processo de revisão difícil, em diálogo com vários familiares, sob a mediação de uma profissional da edição, mas sem o aval direto da autora e em uma condição muito instável de consenso.

\footnotetext{
10 É desta autora mineira a obra Minha vida de menina, muito conhecida no Brasil. É o pseudônimo de Alice Dayrell Caldeira Brant, nascida em Diamantina, em 1880, e falecida no Rio de Janeiro, em 1970. Minha vida de menina foi publicado em 1942, a partir de seu diário de adolescente. Em 1957, foi traduzido ao inglês pela poeta Elizabeth Bishop. Atualmente, é obra encontrada no catálogo da editora Companhia das Letras.

${ }^{11}$ Elzira D. Perpétua, em texto de 2008, já fazia essa aproximação relativa entre revisão e tradução. 0 texto está nos cadernos Viva Voz, publicação da Faculdade de Letras da UFMG, a qual pode ser acessada pelo link:

http://www.letras.ufmg.br/padrao_cms/documentos/eventos/vivavoz/Editora\%C3\%A7\%C3\%A30\%20Art e\%20e\%20T\%C3\%A9cnica site.pdf.
} 


\subsection{Duas línguas quase}

Tratava-se de um livro curto de poemas, de autor vivo, jovem, mas já experiente no campo. A obra sairia entre os volumes de uma coleção de poesia contemporânea cujos títulos eram sempre revisados pela mesma pessoa. Os critérios elencados para as revisões desta coleção levavam em conta o projeto gráfico alegre e arejado; grande respeito aos textos e à autoria, pois todos/as os/as autores eram experientes, alguns já consagrados; e o diálogo com autores, sempre que necessário. Ocorre que os textos eram escritos na língua que o autor chama de "portunhol selvagem", e por isso mesmo ele é conhecido no meio literário.

Que critérios podemos empregar na revisão de textos literários que são escritos numa espécie de "entrelíngua"? Nem uma nem outra; ou ambas. Trata-se de uma revisão e de uma tradução? Como atuar em situações que exigem conhecimento de duas línguas e, mais que isso, a identificação da proposta transgressora de ambas? A graça dos textos poéticos residia não apenas no portunhol ali escrito e levado às últimas consequências, inclusive como língua de literatura. Ao discutir sobre critérios de revisão para esses textos, foi aventado que ao menos as palavras fossem "padronizadas", já que às vezes apareciam grafadas em português, outra vez em espanhol e outra vez nas duas ou em nenhuma delas, no mesmo poema. Mas até isso era um recurso literário e tinha efeitos, inclusive de humor, nas peças. Haverá uma grande frustração quando o/a profissional de revisão não faz sequer uma anotação?

\subsection{Poesia e prosa infantil contemporâneas: restrições?}

As duas experiências anteriores são radicais. Não é comum que revisemos textos literários post mortem ou em línguas semi-inventadas. As experiências que narraremos nesta seção são mais familiares ao/à revisor/a de literaturas, uma vez que dizem respeito a convenções possíveis e a escolhas definidas juntamente com os/as autores/as. A primeira delas é a revisão de um livro de poemas. Diante da 
ocorrência da palavra "minissaia", então grafada pela autora "mini-saia", a despeito das mudanças do Acordo Ortográfico mais recente, que talvez autorizassem a revisora a retirar o hífen e incluir um "s", preferiu-se o diálogo com a poeta. A questão era: podemos atualizar a ortografia? Em alguns segundos, a resposta: “Não, com dois 's' fica muito feio. Deixem como está". E assim foi.

Como um/a revisor/a justifica para si a manutenção da grafia antiga, sem sentir alguma frustração e certo medo de assumir a revisão deste livro? Em que medida seu trabalho será percebido como "erro de revisão" ou como "licença"? Neste caso, era possível considerar, por exemplo, que a poeta preferisse a grafia da época em que o texto foi escrito, mas talvez nem fosse o caso. Por que a forma de uma palavra, a estética mesma de sua escrita, não pode ser um critério acima da correção gramatical? Esta é uma medida cabível para um/a revisor/a diante das escolhas do/a autor/a? Para o/a leitor/a final, se acaso notasse essa grafia, qual seria o "julgamento" e de quem, autora ou revisora? Quantas pessoas vão às páginas de crédito, depois de lerem uma obra editada?

O segundo caso diz respeito a outro tipo de restrição, externa à relação entre revisora e autora, mas muito compreensível no âmbito da edição de livros para crianças e jovens. Ao revisar um livro dirigido a crianças, com personagens crianças, a revisora deparou com uma fala da personagem em forma coloquial, do tipo: "Vou pegar ele lá fora". Diante da possibilidade mais estrita de uma adequação gramatical (pegá-lo), mas também da consideração de que uma fala informal de criança talvez fosse mais verossímil tal como estava escrito, o diálogo entre revisora e autora ocorreu neste sentido: verossimilhança ou adequação formal a uma gramática abstrata, que normalmente não usamos, menos ainda na fala (embora se tratasse, afinal, de um futuro livro impresso)?

O resultado do diálogo foi a mudança de "pegar ele" para "pegá-lo", por decisão da autora e apesar dos argumentos da revisora, que preferia a solução mais oral. O argumento da escritora terminou por vencer outros propósitos. A escolha da construção mais formal e entendida como "correta" ocorreu em razão 
dos editais de compras de livros por várias esferas de governo, algo que esta autora almejava (e que ocorreu, de fato). Segundo ela, entre os critérios para eliminação de obras em editais estavam os "erros de português", risco que ela não queria correr.

De fato, esse critério é explícito e definitivo em formulários de avaliação de obras para compras por editais públicos. A questão é como prever que tipo de avaliação um/a especialista fará de casos como estes, desta seção, a depender de sua compreensão - imprevisível - sobre língua, gramática, adequação e, afinal, literatura e linguagem. Se a autora subestima a avaliação, nesse sentido, a revisora talvez superestime. Eis duas margens difíceis de navegar.

\section{CONCLUSÃO DESTE TEXTO (NÃO SOBRE O TEMA)}

Não pretendíamos, e não o fizemos aqui, discutir a autoria, assunto espinhoso e que mereceu e sempre merece muitos estudos ${ }^{12}$. Supondo, apenas para um exercício, que a autoria seja um espectro, que vá do mais desapegado (múltiplo, anônimo, fantasmático e/ou sem assinatura, público ou coletivo) ao mais apegado (especular quanto ao/à próprio autor/a, pessoal, peculiar, intransferível, dono de estilo e mesmo reconhecível, tão personal é), o texto literário certamente estará no polo do apego em relação à autoria. No entanto, como a literatura surpreende, em seus processos e em seus produtos, há textos literários feitos de cópia, de não-autoria, de remix, de não-original, tal como demonstra Villa-Forte (2019), com base em estudos anteriores. E se assim é, dizemos que para um texto literário é importante que haja uma revisão também literária, i. é, capaz de uma sensibilidade que caminha junto com os (des)limites da própria literatura, em contínua negociação entre esses personagens - autor e revisor -, atentos, ambos, ao projeto de um texto que provavelmente será publicado (e vem sendo editado). Resistimos a falar em negociação entre "pares", dado que há uma concepção

\footnotetext{
12 Em especial, podemos mencionar os estudos de Luciana Salazar Salgado (2017).
} 
circulante, profissional e socialmente forte, de que autor e revisor operam em órbitas diferentes, não sendo exatamente pares, num diálogo portanto assimétrico. Na revisão da literatura, no entanto, assim como em qualquer processo de revisão de textos que possa ser observado de perto, pode ser que enxerguemos um outro cenário, principalmente porque por trás dos papéis de escritor e revisor podem estar pessoas de formação semelhante, isto é, pares em outras cenas, similarmente qualificadas, etc. A ideia de que o/a revisor/a está em posição inferior ou obediente não passa de uma caricatura, como dissemos, aliás cujas rebeldias e insubordinações já foram bem abordadas na literatura ${ }^{13}$.

Do mesmo modo que um/a editor/a pensa e escolhe um/a ilustrador/a para dado texto (se o/a autor/a não for também ilustrador/a), um/a editor/a também, conhecendo o traço de seus revisores (internos ou autônomos), deve pensar sobre quem convidar para dada revisão de texto literário. Existe o risco de que um/a profissional mais "rígido" e mais colado às prescrições gramaticais corrompa um texto literário, para usar um dos termos de Negroni e Estrada (2006), quando deveria auxiliá-lo num voo artístico. Ou o contrário, quando um/a revisor/a mais "permissivo/a" corrompe uma obra que demandava mais rigor e menos liberdade.

Poderíamos, então, afirmar que revisores têm estilos? Talvez não propriamente. Mas podemos dizer que revisores precisam ser sensíveis às linguagens, e às suas próprias condições de sucesso e frustração. Em Goiânia, num evento intitulado Leitura e Resistência (2018), tivemos a oportunidade de oferecer uma oficina de revisão de textos literários contemporâneos, com material autêntico, a um público de cerca de vinte profissionais. A maioria deles já tinha experiência como autônomos/as ou como funcionários/as de instituições públicas e privadas. Na ocasião, ao oferecer textos cada vez mais radicais e experiências compartilhadas de decisão sobre os procedimentos de revisão literária, passamos

\footnotetext{
${ }^{13}$ Em José Saramago, como sabemos, mas também em Maria Valéria Rezende, autora brasileira. Ver palestra sobre o tema no canal da Academia Mineira de Letras:

https://www.youtube.com/watch?v=Q3sP05Wi3so.
} 
a ouvir também as autoavaliações dos/as revisores/as. Para alguns/algumas, a revisão desse tipo de texto era uma alegria, um exercício de liberdade, até mesmo diversão, sem descartar a seriedade e a responsabilidade inerentemente exigidas na tarefa; para outros/as, cada experiência com aqueles textos trazia grande frustração e um pouco de sofrimento, já que "aplicar regras" era muito relativo.

Assim vemos: não há qualquer problema nisso. Problemas há em estabelecer um marco sobre as competências de revisores/as que os tornem profissionais "perfeitos", que sabem tudo a respeito de tudo, que dominam todos os tons e todas as regras, são sensíveis a todas as linguagens e que acumulam um repertório absolutamente invejável de conhecimentos. Nas experiências empíricas, não queremos fazer parecer uma profissão inalcançável; ao contrário: a prática, num rol diverso de oportunidades, deve fazer que cada um/a perceba com que situações se dá melhor, a fim de, se for o caso, se especializar dentro da especialidade, embora possa sempre exercer atividades mais gerais, em diálogo com seus colegas, clientes, formadores e outros profissionais do campo.

É cuidar também para que os incômodos e frustrações do/a revisor/a não se transformem em autoritarismo ou tirania, em situações que deveriam ter sido de colaboração e respeito mútuo. Revisores erram. Se não porque não escrevem (e muitos são também escritores), porque desescrevem o literário dos textos, se não se propuserem o diálogo como estratégia básica de suas práticas profissionais. É o caso de aprender, com Manoel de Barros, que as palavras podem se ajuntar por amor, não por sintaxe.

\section{REFERÊNCIAS}

ALMEIDA, Gisely Pereira de. A revisão do gênero literário: considerações sobre os caminhos entremeados de um texto. Revista do Instituto de Ciências Humanas, v. 14, n. 20, p. 68-94, 2019. Disponível em: http://seer.pucminas.br/index.php/revistaich/article/view/17984. Acesso em: 25 mar. 2020.

BAPTISTA, Patrícia R. Tanuri; RIBEIRO, Ana Elisa; VILELLA, Ana Maria Nápoles. Tecnologias da edição no CEFET-MG: Uma experiência de formação de bacharéis em Letras. In: SALGADO, 
Luciana Salazar; PENTEADO, Ana Elisa de Arruda (Orgs.) Mediação editorial: O que é? Quem faz? Revisão de textos, ofícios correlatos e materialidades editáveis. Bragança Paulista, SP: Margem da Palavra, 2018.

COLLEU, Gilles. La edición independiente como herramienta protagónica de la bibliodiversidad. Trad. Víctor Goldstein. Buenos Aires: La Marca Editora, 2008.

DE DIEGO, José Luis. La otra cara de Jano. Una mirada crítica sobre el libro y la edición. Buenos Aires: Ampersand, 2015.

FRAGO, Juan Antonio. El Quijote, con la arbitraria corrección de al momento por al jumento. Boletín de Filología, tomo LIV, n. 2, p. 375-385, 2019. Disponível em:

https://scielo.conicyt.cl/pdf/bfilol/v54n2/0718-9303-bfilol-54-2-00375.pdf. Acesso em: 25 mar. 2020.

MACHADO, Carolina. Manual de sobrevivência do revisor iniciante. Belo Horizonte: Moinhos, 2018.

MEDEIROS, Nuno. Notas sobre o mundo social do livro: a construção do editor e da edição. Revista Angolana de Sociologia [on-line], 9, p. 32-48, 2012. Disponível em: http://journals.openedition.org/ras/412. Acesso em: 5 dez. 2020.

MUNIZ JR., José de Souza. O mercado profissional e a formação em edição. In: OLIVEIRA, Luiz Henrique Silva de; MOREIRA, Wagner (Orgs.) Edição \& Crítica. Belo Horizonte: CEFET-MG, 2018. Disponível em: http://www.letras.bh.cefetmg.br/wpcontent/uploads/sites/193/2019/04/EDI\%C3\%87\%C3\%830-CR\%C3\%8DTICA-PDF.pdf. Acesso em: 20 mar. 2020.

NEGRONI, María Marta García; ESTRADA, Andrea. ¿Corrector o corruptor? Saberes y competencias del corrector de estilo. Paginas de Guarda, n. 1, otubro, p. 26-40, 2006. Disponível em:

https://www.researchgate.net/publication/28174326 Corrector o corruptor saberes y comp etencias del corrector de estilo. Acesso em: 19 mar. 2020.

OLIVEIRA, Risoleide Rosa Freire de. A atividade de revisão no âmbito editorial. IX CONGRESSO BRASILEIRO DE LINGUÍSTICA APLICADA, Anais eletrônicos... v. 1, n. 1, p.1-16, 2012. Disponível em: https://alab.org.br/wp-content/uploads/2012/04/04 02.pdf. Acesso em: 25 mar. 2020.

PEREZ, Marcelo Spalding; BOENAVIDES, William Moreno. Os limites para a revisão do texto literário a partir dos conceitos de autoria e estilo de Bakhtin. Bakhtiniana, v. 12, n. 1, p. 113130, abr. 2017. Disponível em: http://www.scielo.br/pdf/bak/v12n1/2176-4573-bak-12-010113.pdf. Acesso em: 25 mar. 2020.

PINTO, Bethânia Ferreira; MARQUES, Penélope Castro. Revisor de texto literário e roteirista de adaptação literária: o diálogo entre duas profissões. Revista do Instituto de Ciências Humanas, v. 15, n. 23, p. 161-173, 2019. Disponível em: 
http://periodicos.pucminas.br/index.php/revistaich/article/view/17794. Acesso em: 25 mar. 2020.

PERPÉTUA, Elzira Divina; GUIMARÃES, Raquel Beatriz Junqueira. A revisão do texto literário: um trabalho de memória. Scripta, v. 14, n. 26, p. 195-204, 2010. Disponível em:

http://periodicos.pucminas.br/index.php/scripta/article/view/4360/4505. Acesso em: 25 mar. 2020.

RIBEIRO, Ana Elisa. Livro: edição e tecnologias no século XXI. Belo Horizonte: Moinhos/Contafios, 2018.

SALGADO, Luciana Salazar. Quem mexeu no meu texto? Divinópolis, MG: Artigo A, 2017. (Questões contemporâneas de edição, preparação e revisão textual).

\section{Ana Elisa Ribeiro}

Doutora em Estudos Linguísticos

https://orcid.org/0000-0002-4422-7480 • anadigitalpro@gmail.com 